\title{
COMPORTAMENTO DOCENTE NO ENSINO DE GRADUAÇÃO EM ENFERMAGEM: A PERCEPÇÃO DOS ALUNOS*
}

\author{
Maria da Graça da Silva** \\ Márcia Caron Ruffino***
}

SILVA, M.da G.; RUFFINO, M.C. Comportamento docente no ensino de graduação em enfermagem: a percepção dos alunos. Rev.latino-am.enfermagem, Ribeirão Preto, v. 7, n. 4, p. 45-55, outubro 1999.

Este trabalho é um estudo tipo levantamento tendo como objetivos: identificar os comportamentos docentes predominantes no ensino de graduação em enfermagem, de acordo com a percepção dos alunos, agrupando-os em tipos de professor e relacionando-os com as abordagens de ensino. Os dados foram obtidos através de formulário, aplicado a 52 sujeitos, alunos do curso de graduação em Enfermagem da Universidade Federal de Mato Grosso do Sul. Considerando os resultados obtidos em ambas as séries, pode-se dizer que há pluralidade de comportamentos docentes, predominando professores preocupados com conteúdos, métodos e técnicas, com características das concepções tradicional, comportamental e cognitivista.

\section{UNITERMOS: abordagens de ensino; comportamento docente; ensino de graduação}

\section{INTRODUÇÃO}

Entendendo educação como algo amplo, contínuo e criativo, pesquisa torna-se instrumento essencial na sua realização, sendo meio para o desenvolvimento profissional dos professores, essencial para a melhoria de sua ação na sala de aula e para a construção do conhecimento sobre o ensino.

Conforme SOUZA (1992) os enfermeiros que trabalham na educação formal, ou seja, nas escolas de enfermagem, têm responsabilidade em relação à necessidade de refletir, de criticar os programas e métodos utilizados na formação de seus alunos. É necessário buscar respostas às questões de ensino e com base nos dados obtidos, reformular conteúdos e objetivos do programa escolar, sem omitir problemas sociais e regionais intrínsecos à nossa profissão.

Atuar em educação necessita conhecimento das diferentes abordagens de ensino ou tendências pedagógicas, que podem nortear a prática docente, sabendo que as mesmas refletem o caráter ideológico que perpassa o sistema educacional de contextos determinados. É necessário que os educadores, através da consciência crítica, reavaliem os modelos educacionais e analisem as influências exercidas por eles na sua prática educativa.

À medida em que incorporamos e assumimos o papel de educadora, enquanto enfermeira, entendemos educador como proposto por LUCKESI (1994, p. 24): ser humano e profissional envolvido em uma prática histórica e contextualizada, o ato de ensinar torna-se inquietação.
Ao tentarmos identificar, através da percepção dos alunos, as abordagens pedagógicas que docentes do curso de graduação em enfermagem da Universidade Federal de Mato Grosso do Sul estão utilizando, inferidas a partir da análise dos comportamentos dos professores, pretendemos despertar interesse pelas questões do ensino e da formação profissional do enfermeiro, na expectativa de aprofundarmos as discussões referentes a esse assunto e estabelecermos atitudes socialmente comprometidas.

Com base nessas considerações, os objetivos deste estudo são:

GERAL

- Fomentar discussões entre docentes de Enfermagem, pelas questões do ensino e da formação pedagógica e profissional do enfermeiro docente.

\section{ESPECÍFICOS}

- Identificar comportamentos docentes predominantes no ensino de enfermagem, segundo a percepção dos alunos de graduação;

- Agrupar os comportamentos identificados em cinco tipos de professores, relacionando-os com as abordagens de ensino.

\section{REFERENCIAL TEÓRICO}

Estudiosos na área da Educação classificam as abordagens de ensino de modo sistemático para melhor analisá-las, no entanto, sabem que elas não aparecem em sua forma completa, não são mutuamente exclusivas e abrangem aspectos parciais da riqueza e da prática escolar. Apresentaremos a classificação proposta por

\footnotetext{
* Dissertação de mestrado, apresentada ao programa de Pós-Graduação da Escola de Enfermagem de Ribeirão Preto da Universidade de São Paulo, Área Enfermagem Fundamental, outubro/97, sob orientação da Prof ${ }^{\mathrm{a}}$ Dr $^{\mathrm{a}}$ Márcia Caron Ruffino

** Enfermeira. Mestre em Enfermagem Fundamental. Docente na Universidade Federal de Mato Grosso do Sul

*** Professora Titular, aposentada, do Departamento de Enfermagem Geral e Especializada da Escola de Enfermagem de Ribeirão Preto da Universidade de São Paulo
} 
MIZUKAMI (1986), adotada como referencial teórico neste trabalho, pois acreditamos que a mesma possibilita uma visão esquematizada e resumida dos pressupostos teóricos e metodológicos de cada abordagem, permitindo que o professor avalie sua prática em sala de aula.

\section{Abordagem humanista}

Os pressupostos da abordagem humanista têm sua origem nos trabalhos de Carl Rogers, psicólogo americano, e surgiram embasados na sua experiência como terapeuta, sendo posteriormente adaptados à educação, em seus quarenta anos de "experiência didática”.

Segundo ROGERS \& ROSENBERG (1977) o mais importante dentro de todo processo educacional é o ser humano, tantas vezes menosprezado e manipulado. Esses autores trazem os fundamentos do ensino centrado na pessoa, onde o foco de aprendizagem volta-se para quem aprende e não para quem ensina e ainda valoriza a relação professor-aluno e a auto-educação. No humanismo, na opinião de ALMEIDA (1992), o eixo principal é o sentimento, o aspecto psicológico do aluno. A educação é vista como terapia e a transmissão de conteúdos torna-se secundária.

FERRETTI (1989) coloca que nessa abordagem existe uma relação de cooperação entre professor e alunos: o docente é mais do que transmissor de informações; é um facilitador/estimulador da aprendizagem, cujo papel principal é o de preparar e garantir as situações de aprendizagem. Na opinião de SAVIANI (1989) a concepção humanista conduz à educação centrada no educando, na vida, na atividade, com predominância do psicológico sobre o lógico. O homem é considerado um ser inacabado que tem de estar predisposto e atento para aprender.

\section{Abordagem tradicional}

Essa abordagem apresenta-se como uma prática educativa transmitida através dos anos, não se fundamentando em teorias. O ensino é centrado no professor e está voltado para os aspectos externos do processo, como estratégias de ensino e planejamento. $\mathrm{O}$ docente espera que o aluno dê respostas que coincidam com aquelas que ele (professor) estabeleceu como corretas para os problemas formulados.

O professor é transmissor de conteúdos, preocupado em cumprir objetivos e metas, prazos e prescrições; ele detém o poder decisório quanto à metodologia, conteúdo, avaliação e forma de interação com aluno. $\mathrm{O}$ aluno deve reproduzir os dados fornecidos e executar as orientações do professor, o qual detém o poder, a autoridade e o conhecimento.

Predomina a palavra do professor; educando é ouvinte, educador é narrador, dissertador que utiliza seu "saber" como instrumento de coerção para instaurar o poder na sala de aula. O sentido tradicional da educação, na opinião de BALZAN (1989), está na excessiva verbalização dos professores, os quais sendo incapazes de estimular a ação dos alunos em sala de aula, utilizamse do monólogo.

A relação estabelecida entre professor e alunos é vertical, unilateral e de dependência, inexistindo a formação de grupo para que não ocorra interação entre os estudantes. No exposto por BORDENAVE (1982) o aluno deve receber informações, tomar nota e memorizar passivamente conteúdos, respeitando o professor e os livros, mesmo que exista distância entre teoria e prática e os conhecimentos repassados pertençam a outra realidade. $\mathrm{O}$ docente regula o tempo, o espaço e os papéis dos envolvidos na relação estabelecida no contexto escolar.

\section{Abordagem comportamental}

Segundo MIZUKAMI (1986) tal abordagem caracteriza-se por considerar o indivíduo sujeito às contingências do meio, sendo o conhecimento uma cópia de algo que simplesmente ocorre no mundo externo. A base do conhecimento está na experiência ou na experimentação planejada e implica em recompensa e controle; planejamento das experiências e das atividades de aprendizagem bem como na modelagem do comportamento humano através de reforços.

A transmissão de conteúdos visa objetivos e habilidades que levem à competência e utiliza aparato tecnológico - educacional para atingi-los, com a aplicação de conhecimentos científicos e técnicas em sala de aula, sem envolvimento pessoal do professor.

A educação decorrente dessa abordagem preocupa-se com os elementos mensuráveis e observáveis do comportamento dos alunos. "O ensino é, pois, composto por padrões de comportamento que podem ser mudados através de treinamento, segundo objetivos pré fixados" (MIZUKAMI, 1986, p.20).

A finalidade básica do sistema educacional é promover mudanças nos indivíduos, reforçando comportamentos culturalmente aceitáveis e introduzindo outros considerados necessários. "O comportamento é moldado a partir da estimulação externa, portanto o indivíduo não participa das decisões curriculares que são tomadas por um grupo do qual ele não faz parte" (MIZUKAMI, 1986, p.28).

A ênfase, de acordo com BORDENAVE (1982), está nos resultados comportamentais. O professor estabelece objetivos instrucionais quantitativamente mensuráveis sem considerar a transmissão de idéias ou conhecimentos; o importante é o aprendiz dar as respostas esperadas, condicionado através de um processo estímuloresposta-reforço.

\section{Abordagem sociocultural}

O ponto de partida aqui é sempre o conteúdo 
advindo daquilo que é cultural, isto é, o que as pessoas construíram e assimilaram enquanto sujeitos de sua própria experiência, o universo real de conhecimentos do educando, não se fornecendo coisas prontas e extraídas do ambiente externo. É importante o que o aluno traz para o processo de aprendizagem: conhecimentos, capacidades e destreza prévias; percepção da escola, do professor e de suas atuações; expectativas e atitudes diante do ensino, escola e professor; motivações, interesses, crenças e atribuições.

"Não podemos desligar a aprendizagem do aluno do contexto social e interpessoal no qual, inevitavelmente, é produzida. $\mathrm{O}$ aluno constrói seu conhecimento a partir de conteúdos escolares culturalmente determinados, através de sua assimilação e apropriação pessoal, atribuindo-lhes um conjunto de significados que vão além de simples recepção passiva" (COLL \& SOLÉ, 1996, p.281).

FREIRE \& MACEDO (1990) afirmam que todo educador crítico é também educando e que os professores devem aprender com seus alunos através do diálogo; que tanto alunos quanto professores precisam assumir o papel de sujeitos cognoscentes, isto é, sujeitos que conhecem.

A prática transformadora procura desmitificar e questionar a cultura dominante, criando condições para o aluno analisar o contexto de acordo com seus valores. Existe preocupação com cada aluno em si e com o processo; os alunos, participando desse processo com o professor, tornam-se sujeitos elaboradores e criadores de conhecimento. Os indivíduos são considerados seres concretos, situados no tempo e no espaço, inseridos em contexto histórico, no qual a educação deve promover o indivíduo, e não ajustá-lo à sociedade em que vive.

A tendência sócio cultural visa comprometer os alunos com problemas de seu ambiente. A relação professor - aluno é horizontal e não imposta, onde ambos aprendem e ensinam; o professor deve criar, junto com a classe, condições para a percepção e discussão das contradições da sociedade da qual eles fazem parte.

\section{Abordagem cognitivista}

Seus adeptos enfatizam os processos cognitivos de aprendizagem e sua articulação com as emoções. Tais processos são elementos que constituem a força interacionista dessa abordagem. O conhecimento é produto da interação homem-mundo. O desenvolvimento da inteligência ocorre por estágios que se sucedem do mais simples ao mais complexo, em interdependência com o desenvolvimento simultâneo da afetividade.

$\mathrm{O}$ indivíduo é considerado um sistema aberto, em processo progressivo de adaptação (assimilação e acomodação sucessivas), em busca de estágios superiores da inteligência, isto é, o ser humano progride de estágios mais primitivos em direção ao pensamento hipotético dedutivo, elaborando conhecimentos nos níveis sensório - motor, perceptivo, lógico - concreto e lógico - abstrato.
A educação cognitivista, baseada nos princípios de PIAGET, tem por objetivo a apreensão de verdades, informações, demonstrações e modelos para autonomia moral e intelectual. O ensino concentra-se no "como" o aluno aprende e relaciona conhecimentos com o meio em que vive, fundamentado na pesquisa, na investigação e na solução de problemas, consistindo em processos e não em produtos de aprendizagem.

O professor que adota tal abordagem propõe desafios aos alunos, para que esses sejam elementos ativos de sua aprendizagem, observando, experimentando, comprovando, relacionando conteúdos. No entanto, o professor domina o conteúdo de sua disciplina, sua estrutura e objetivos, elementos com os quais constrói as situações - problemas para os estudantes.

\section{Diversos tipos de professores}

BORDENAVE \& PEREIRA (1994) consideram que cada professor é um ser humano com crenças e emoções diversas e, dependendo de sua metodologia, pode contribuir para gerar uma consciência crítica ou uma memória fiel, uma visão universalista ou uma visão estreita e unilateral, uma sede de aprender pelo prazer de aprender e resolver problemas ou uma angústia de aprender apenas para receber um prêmio e evitar um castigo.

Esses autores relatam um estudo feito pela Universidade da Califórnia - EUA, estabelecendo cinco tipos de professores de acordo com a abordagem adotada no ensino.

\section{A - O instrutor ou professor de autômatos}

O tipo instrutor ajuda o aluno a desenvolver a memória, sem necessidade de pensar. Nas aulas, o estudante recita conteúdos a partir das exposições do professor ou de textos e apostilas. O aluno torna-se um autômato que emite as respostas corretas. $\mathrm{O}$ instrutor é a autoridade máxima.

\section{B - O professor que se concentra no conteúdo}

Concentrando-se nas matérias de sua disciplina, esse professor considera irrelevante as questões sobre o processo ensino - aprendizado. Utiliza a pesquisa apenas como "artifício didático"; valoriza a aprendizagem de toda matéria, atual e passada, menosprezando a criatividade e originalidade do aluno. A discussão entre professor e aluno é vista como dispensável e não interfere no objetivo de ensinar ou aprender.

\section{C - O professor que se concentra no processo de instrução}

Esse tipo preocupa-se em conseguir a reprodução e imitação, pelos seus alunos, dos mesmos métodos e 
processos que ele usa, impondo um modelo de raciocínio onde prevalecem suas idéias, perspectivas e maneira de utilizar os conteúdos existentes.

Pode transmitir a impressão de autoridade e independência, pois favorece o diálogo com estudantes, entretanto, tudo começa e termina com ele e suas idéias, interessando o "processo de saber" mais do que o saber como produto.

\section{D - O professor que se concentra no intelecto do aluno}

Nesse caso o processo de ensino e de aprendizagem concentra-se na própria atividade racional, sendo importante como e porquê se aprende, não o quê. A preocupação está no desenvolvimento das habilidades intelectuais do aluno, porém são irrelevantes as atitudes e emoções do mesmo. Utiliza a análise e solução de problemas como um recurso didático, mas não se compromete como pessoa.

\section{E - O professor que se concentra na pessoa total}

$\mathrm{O}$ estudante constitui o centro do processo para esse professor, cuja crença é de que o desenvolvimento intelectual está ligado aos aspectos afetivos e não racionais da personalidade. Considera o ensino como um desafio, incentivando o aluno a buscar respostas e acreditando que tratando o estudante como pessoa integral estará auxiliando seu processo de crescimento como adulto.

BORDENAVE \& PEREIRA (1994) apontam a existência de um outro tipo de professor, mais encontrado nos países em desenvolvimento, ao qual denominaram: o professor que tem uma visão estrutural da sociedade, que considera o aluno, as matérias a ensinar e a si mesmo como partes inseparáveis de um contexto social, de uma sociedade historicamente estruturada.

\section{METODOLOGIA}

O presente estudo foi desenvolvido junto a alunos do curso de graduação em Enfermagem e Obstetrícia da Universidade Federal de Mato Grosso do Sul, na cidade de Campo Grande - MS.

A amostra foi composta por alunos matriculados na $3^{\mathrm{a}}$ e $4^{\mathrm{a}}$ séries do curso de graduação em enfermagem (do $5^{\circ}$ ao $8^{\circ}$ semestre), sendo 42 alunos matriculados na $3^{\mathrm{a}}$ série e 23 na $4^{\mathrm{a}}$ série. A maioria dos estudantes era do sexo feminino. A participação na pesquisa era voluntária e dependia da presença em sala de aula no dia da coleta dos dados e no momento da aplicação do instrumento.

Participaram como sujeitos do estudo 32 alunos da $3^{\mathrm{a}}$ série $\left(5^{\circ} / 6^{\circ}\right.$ semestre $)$ e 20 alunos da $4^{\mathrm{a}}$ série $\left(7^{\circ} / 8^{\circ}\right.$ semestre). Essas séries foram selecionadas devido ao fato desses alunos já terem vivenciado diferentes situações de ensino com vários professores.

Os dados foram coletados através de formulário, acompanhado de escala tipo LIKERT (Anexo 1), contendo proposições relacionadas aos comportamentos do professor, e agrupadas em cinco tipos de professores (Anexo 2), de acordo com as diferentes abordagens de ensino. A coleta foi realizada durante o mês de julho de 1996, com autorização prévia da coordenadora do curso e em momento oportuno acertado anteriormente com os professores das séries.

A escala tipo LIKERT é um tipo de escala sócio - psicológica, utilizada para medir, quantitativamente, atitudes, medos, motivos e percepções entre diferentes pessoas, sobre determinado objeto. Tal instrumento consiste em várias afirmações declarativas, denominadas itens, que expressam um ponto de vista sobre um tópico. Aos respondentes solicita-se que indiquem o grau de concordância ou discordância com a opinião expressa pela declaração. A característica concisa da escala de LIKERT, torna possível fazer boa discriminação entre pessoas com diferentes pontos de vista (POLIT \& HUNGLER, 1993).

Os dados foram analisados quantitativamente através de técnicas estatísticas descritivas de medidas de tendência central: média aritmética, moda e mediana. Para inferência estatística foram realizados análise da variância e teste de DUNCAN.

A análise da variância serve para testar a hipótese nula, segundo a qual duas ou mais médias provêm da mesma população, ou se diferentes tratamentos têm efeito idêntico, quando aplicados a uma mesma população. É provavelmente, o método estatístico de maior utilização em psicologia e educação (RODRIGUES, 1975). Tal análise permitiu observar se as médias encontradas para os tipos de professor apresentavam diferença significante entre si.

O teste de DUNCAN é utilizado para verificação da significância da diferença entre pares de médias; é um teste de fácil emprego e de bastante eficácia (RODRIGUES, 1975).

\section{RESULTADOS}

Apresentamos a análise comparativa dos comportamentos docentes segundo a percepção dos alunos separados por série, nas tabelas e gráficos(Anexo 3). A Tabela 1 exibe a numeração das proposições, seus respectivos escores em cada série, bem como a porcentagem de sujeitos concordantes e discordantes.

$\mathrm{Na}$ Tabela 2, observa-se a distribuição do número de sujeitos concordantes e discordantes, para cada proposição e por série.

Observa-se que os sujeitos das duas séries estudadas, em termos de concordância, apresentam amplitudes proporcionalmente semelhantes e acima de $50 \%$ para os itens que descrevem comportamentos relacionados a uma abordagem tradicional de ensino, com exceção dos números 6, 20 e 24. 
Tabela 1 - Distribuição das proposições com escores separados por série e porcentagem de sujeitos concordantes e discordantes. Campo Grande-MS, 1997

\begin{tabular}{|c|c|c|c|c|c|c|}
\hline & \multicolumn{2}{|c|}{ CONCORDÂNCIA } & \multicolumn{2}{|c|}{ DIS C ORDÂNCIA } & \multicolumn{2}{|c|}{ ESCORES TOTAIS } \\
\hline & $3^{2}$ SÉRIE & $4^{2}$ SÉRIE & $3^{2}$ SÉRIE & $4^{2}$ SÉRIE & $3^{2}$ SÉRIE & $4^{2}$ SÉRIE \\
\hline PROP OSIÇÃO & $\%$ & $\%$ & $\%$ & $\%$ & TOTAL & TOTAL \\
\hline 1 & 58 & 30 & 44 & 70 & 77 & 36 \\
\hline 2 & 69 & 90 & 32 & 10 & 90 & 64 \\
\hline 3 & 69 & 75 & 32 & 25 & 92 & 61 \\
\hline 4 & 60 & 35 & 41 & 65 & 79 & 40 \\
\hline 5 & 47 & 65 & 53 & 35 & 77 & 57 \\
\hline 6 & 91 & 80 & 9 & 20 & 109 & 58 \\
\hline 7 & 62 & 25 & 37 & 75 & 77 & 35 \\
\hline 8 & 28 & 75 & 72 & 25 & 69 & 61 \\
\hline 9 & 88 & 40 & 12 & 60 & 107 & 49 \\
\hline 10 & 3 & 10 & 97 & 90 & 38 & 25 \\
\hline 11 & 72 & 85 & 28 & 15 & 99 & 68 \\
\hline 12 & 6 & 5 & 94 & 95 & 46 & 27 \\
\hline 13 & 75 & 80 & 26 & 20 & 98 & 65 \\
\hline 14 & 25 & 30 & 75 & 70 & 57 & 41 \\
\hline 15 & 3 & 0 & 97 & 100 & 39 & 23 \\
\hline 16 & 3 & 15 & 97 & 85 & 39 & 29 \\
\hline 17 & 13 & 5 & 87 & 95 & 51 & 30 \\
\hline 18 & 25 & 25 & 75 & 75 & 56 & 39 \\
\hline 19 & 57 & 50 & 44 & 50 & 78 & 43 \\
\hline 20 & 60 & 70 & 41 & 30 & 83 & 52 \\
\hline 21 & 82 & 100 & 18 & 0 & 101 & 74 \\
\hline 22 & 57 & 70 & 44 & 30 & 81 & 55 \\
\hline 23 & 66 & 35 & 35 & 65 & 84 & 42 \\
\hline 24 & 50 & 60 & 50 & 40 & 78 & 52 \\
\hline 25 & 37 & 70 & 62 & 30 & 67 & 54 \\
\hline
\end{tabular}

Tabela 2 - Distribuição do número de sujeitos concordantes e discordantes, para cada proposição e por série. Campo Grande-MS, 1997

$$
\begin{gathered}
\mathbf{3}^{2} \text { SÉRIE } \\
\text { (TOTAL }=32 \text { SUJEITOS) }
\end{gathered}
$$

\begin{tabular}{ccccc}
\hline PROP OSIÇÃO & Concordância & Discordância & Concordância & Discordância \\
\hline $\mathbf{1}$ & 18 & 14 & 6 & 14 \\
\hline $\mathbf{2}$ & 22 & 10 & 18 & 2 \\
\hline $\mathbf{3}$ & 22 & 10 & 15 & 5 \\
\hline $\mathbf{4}$ & 19 & 13 & 7 & 7 \\
\hline $\mathbf{5}$ & 15 & 17 & 13 & 4 \\
\hline $\mathbf{6}$ & 29 & 3 & 16 & 15 \\
\hline $\mathbf{7}$ & 20 & 12 & 5 & 5 \\
\hline $\mathbf{8}$ & 9 & 23 & 15 & 12 \\
\hline $\mathbf{9}$ & 28 & 4 & 8 & 18 \\
\hline $\mathbf{1 0}$ & 1 & 31 & 2 & 3 \\
\hline $\mathbf{1 1}$ & 23 & 9 & 17 & 19 \\
\hline $\mathbf{1 2}$ & 2 & 30 & 1 & 14 \\
\hline $\mathbf{1 3}$ & 24 & 8 & 16 & 20 \\
\hline $\mathbf{1 4}$ & 8 & 24 & 6 & 17 \\
\hline $\mathbf{1 5}$ & 1 & 31 & 0 & 19 \\
\hline $\mathbf{1 6}$ & 1 & 31 & 3 & 15 \\
\hline $\mathbf{1 7}$ & 4 & 28 & 1 & 10 \\
\hline $\mathbf{1 8}$ & 8 & 24 & 5 & 6 \\
\hline $\mathbf{1 9}$ & 18 & 14 & 10 & 0 \\
\hline $\mathbf{2 0}$ & 19 & 13 & 14 & 6 \\
\hline $\mathbf{2 1}$ & 26 & 6 & 20 & 13 \\
\hline $\mathbf{2 2}$ & 18 & 14 & 14 & 8 \\
\hline $\mathbf{2 3}$ & 21 & 11 & 7 & 6 \\
\hline $\mathbf{2 4}$ & 16 & 16 & 12 & 14 \\
\hline $\mathbf{2 5}$ & 12 & 14 & & \\
\hline
\end{tabular}


Percebe-se que aqueles comportamentos que indicam falta de compromisso do docente com o ensino e com os alunos (itens 10, 14 e 16), apresentam elevado índice de discordância (acima de $50 \%$ ), podendo significar que os sujeitos de ambas as séries discordam que tais comportamentos predominem entre seus professores.

Nota-se que existe equilíbrio na $3^{\mathrm{a}}$ série em relação à concordância e discordância para a proposição 1 ("Compreendem o aluno como pessoa e facilitam seu processo de aprendizagem"), o mesmo não ocorrendo na $4^{\mathrm{a}}$ série, que mais discordou do que concordou com o comportamento descrito no item.

Ambas as séries mais concordam que discordam dos comportamentos descritos nos itens $2,3,6,11,13$, 20, 21 e 22, estando entre esses itens aqueles que descrevem a abordagem tradicional de ensino. Nos itens 4, 7, 9 e 23, aparecem diferenças entre as séries, sendo que os alunos da $3^{\mathrm{a}}$ série mais concordaram do que discordaram dos comportamentos.

Quanto às proposições 10, 12, 14, 15, 16, 17 e 18 , as opiniões são semelhantes, com ambas as séries mais discordando do que concordando com as afirmações. Já o item 8("transmitem informações de forma mecânica com poucas interpretações"), aparece com maior discordância na $3^{\mathrm{a}}$ série e maior concordância na $4^{\mathrm{a}}$ série. A proposição 19("discutem com os alunos o processo de ensinar e aprender, incentivando a participação e interesse dos mesmos na busca de soluções para questões do ensino e da aprendizagem"), apresentou equilíbrio na concordância e discordância em ambas as séries, parecendo que alguns professores demonstram tal comportamento e outros não.

Quanto ao resultado relativo à proposição 19 , pode ser opção de cada professor comportar-se da maneira referida, de acordo com suas convicções pessoais a respeito da participação dos alunos no processo de ensino e aprendizado.

O comportamento descrito no item 24 ("Preocupam-se com os resultados das provas (notas) e não com a aprendizagem, mas aplicam provas coerentes com os objetivos do disciplina") obteve igualdade na concordância e discordância na $3^{\mathrm{a}}$ série, no entanto, a $4^{\mathrm{a}}$ série mais concorda que discorda da existência de tal comportamento. Tal fato se repete com o item 25 ("Dialogam com os alunos aparentando postura democrática") que, entretanto, pode ter sido interpretado de modo diferente nas séries.

A Tabela 3 mostra os valores atribuídos pelos alunos da $3^{\mathrm{a}}$ série a cada tipo de professor.

Verificou-se o grau de significância da diferença entre as médias relativas a cada um dos tipos, através do teste de DUNCAN, aplicado a posteriori, onde obtevese o seguinte resultado: primeiro o tipo A; segundo os tipos $\mathrm{B}$ e E; terceiro o tipo $\mathrm{C}$ e por último o tipo $\mathrm{D}$. $\mathrm{O}$ esquema a seguir apresenta os dados mostrando que não houve diferença significante entre os tipos C, E, B e A, mas houve entre esses e o tipo D.

$\mathrm{Na}$ Tabela 4, observa-se os valores atribuídos pelos alunos da $4^{\text {a }}$ série a cada um dos tipos de professores. Na aplicação, a posteriori, do teste de DUNCAN, verificou-se que houve diferença significante entre os tipos $\mathrm{A}, \mathrm{B}, \mathrm{C}$ e $\mathrm{E}$ com o tipo $\mathrm{D}$; não houve diferença entre: tipos $\mathrm{E}$ e $\mathrm{C}, \mathrm{B}$ e $\mathrm{A}$, mas a diferença foi significante entre os tipos: E e B; E e A; C e B e C e A. O tipo A ficou, como na outra série, em primeiro lugar, seguido do tipo $\mathrm{B}$; tipo $\mathrm{C}$ em terceiro; em quarto, tipo $\mathrm{E}$ e também em quinto lugar, o tipo $\mathrm{D}$, em igualdade com a percepção dos sujeitos da $3^{\mathrm{a}}$ série.

Tabela 3 - Distribuição dos valores atribuídos pelos alunos da $3^{\text {a }}$ série aos tipos de professor. Campo Grande-MS, 1997

\begin{tabular}{|c|c|c|c|c|c|}
\hline \multirow[b]{2}{*}{ Sujeitos } & \multicolumn{5}{|c|}{ TIPOS DE PROFESSOR } \\
\hline & A & $\mathbf{B}$ & C & D & $\mathbf{E}$ \\
\hline 1 & 12 & 13 & 13 & 8 & 15 \\
\hline 2 & 11 & 15 & 12 & 6 & 6 \\
\hline 3 & 18 & 8 & 13 & 6 & 13 \\
\hline 4 & 12 & 16 & 11 & 7 & 12 \\
\hline 5 & 16 & 14 & 9 & 5 & 7 \\
\hline 6 & 17 & 13 & 13 & 9 & 15 \\
\hline 7 & 10 & 13 & 12 & 9 & 15 \\
\hline 8 & 14 & 12 & 17 & 9 & 15 \\
\hline 9 & 11 & 13 & 14 & 10 & 16 \\
\hline 10 & 17 & 12 & 13 & 6 & 10 \\
\hline 11 & 11 & 12 & 14 & 10 & 14 \\
\hline 12 & 18 & 13 & 9 & 11 & 12 \\
\hline 13 & 14 & 12 & 13 & 5 & 9 \\
\hline 14 & 10 & 15 & 11 & 8 & 15 \\
\hline 15 & 18 & 13 & 7 & 5 & 8 \\
\hline 16 & 13 & 14 & 11 & 8 & 16 \\
\hline 17 & 14 & 14 & 14 & 7 & 15 \\
\hline 18 & 18 & 10 & 11 & 8 & 10 \\
\hline 19 & 11 & 12 & 12 & 7 & 18 \\
\hline 20 & 20 & 10 & 8 & 7 & 7 \\
\hline TOTAL & 285 & 254 & 237 & 151 & 248 \\
\hline MÉDIA & 14,25 & 12,7 & 11,85 & 7,55 & 12,4 \\
\hline
\end{tabular}

Tipos: A- tradicional; B- cognitivista; C- comportamentalista; Dhumanista; E-sociocultural

Teste de DUNCAN aplicado à $3^{\text {a }}$ série

\begin{tabular}{|r|c|c|c|c|c|c|}
\hline TIPOS & D & C & E & B & A & \\
\hline MÉDIAS & $\overline{\mathrm{X}} 4$ & $\overline{\mathrm{X}} 3$ & $\overline{\mathrm{X}} 5$ & $\overline{\mathrm{X}} 2$ & $\overline{\mathrm{X}} 1$ & $\begin{array}{c}\text { Amplitudes } \\
\text { minimas } \\
\text { significantes. } \\
(\mathrm{p}=0,05)\end{array}$ \\
& & & & & & \\
7,6 & & 11,6 & 12,4 & 12,7 & 14,3 & \\
11,9 & & $4,3^{*}$ & $4,8^{*}$ & $5,1^{*}$ & $6,7^{*}$ & $\mathrm{~A} 2=2,45$ \\
12,4 & & - & 0,5 n.s. & $0,8 \mathrm{n} . \mathrm{s}$. & $2,4 \mathrm{n} . \mathrm{s}$. & $\mathrm{A} 3=2,56$ \\
12,7 & & & - & 0,3 n.s. & 1,9 n.s. & $\mathrm{A} 4=2,63$ \\
$\mathrm{~A} 5=2,68$
\end{tabular}

* diferença significante

n.s. = diferença não significante 
Tabela 4 - Distribuição dos valores atribuídos pelos alunos da $4^{\text {a }}$ série aos tipos de professor. Campo Grande-MS, 1997

\section{TIPOS DE PROFESS OR}

\begin{tabular}{cccccc}
\hline Sujeitos & A & B & C & D & E \\
\hline 1 & 19 & 13 & 15 & 8 & 15 \\
\hline 2 & 11 & 11 & 9 & 11 & 12 \\
\hline 3 & 17 & 16 & 14 & 7 & 10 \\
\hline 4 & 19 & 15 & 11 & 9 & 11 \\
\hline 5 & 12 & 14 & 14 & 8 & 16 \\
\hline 6 & 16 & 13 & 10 & 9 & 17 \\
\hline 7 & 14 & 12 & 9 & 7 & 7 \\
\hline 8 & 15 & 15 & 12 & 7 & 14 \\
\hline 9 & 14 & 15 & 15 & 6 & 12 \\
\hline 10 & 19 & 16 & 9 & 5 & 10 \\
\hline 11 & 12 & 16 & 13 & 9 & 16 \\
\hline 12 & 15 & 15 & 10 & 9 & 9 \\
\hline 13 & 17 & 17 & 8 & 5 & 7 \\
\hline 14 & 16 & 11 & 10 & 11 & 9 \\
\hline 15 & 18 & 16 & 8 & 5 & 6 \\
\hline 16 & 18 & 12 & 8 & 7 & 10 \\
\hline 17 & 16 & 13 & 12 & 7 & 6 \\
\hline 18 & 12 & 9 & 11 & 8 & 8 \\
\hline 19 & 16 & 14 & 11 & 11 & 7 \\
\hline 20 & 16 & 16 & 12 & 7 & 13 \\
\hline TOTAL & 312 & 279 & 221 & 156 & 215 \\
\hline MÉDIA & 15,60 & 13,95 & 11,05 & 7,80 & 10,75 \\
\hline
\end{tabular}

Tipos: A- tradicional; B- cognitivista; C- comportamentalista; Dhumanista; E- sociocultural

Teste de DUNCAN aplicado à $4^{\mathrm{a}}$ série

\begin{tabular}{|r|l|c|c|c|c|c|}
\hline TIPOS & D & E & C & B & A & \\
\hline MÉDIAS & $\overline{\mathrm{X}} 4$ & $\overline{\mathrm{X}} 5$ & $\overline{\mathrm{X}} 3$ & $\overline{\mathrm{X}} 2$ & $\overline{\mathrm{X}} 1$ & $\begin{array}{c}\text { Amplitudes } \\
\text { mínimas } \\
\text { sgrificantes } \\
(\mathrm{p}=0,01)\end{array}$ \\
& & & & & & \\
7,8 & 7,8 & 10,8 & 11,1 & 14,0 & 15,6 & \\
10,8 & & $3,0^{*}$ & $3,3^{*}$ & $6,2^{*}$ & $7,8^{*}$ & $\mathrm{~A} 2=2,21$ \\
11,1 & & & 0,3 n.s. & $3,2^{*}$ & $4,8^{*}$ & $\mathrm{~A} 3=2,31$ \\
14,0 & & & - & $2,9^{*}$ & $4,5^{*}$ & $\mathrm{~A} 4=2,37$ \\
1,6 .s. & $\mathrm{A} 5=2,42$ \\
\hline
\end{tabular}

* diferença significante

n.s. = diferença não significante

Na comparação entre as séries, pode-se notar que a diferença entre as médias é significante apenas quanto ao tipo $\mathrm{E}$, sendo a média da $3^{\mathrm{a}}$ série superior à da $4^{\mathrm{a}}$ série (Tabela 5).

Tais dados permitem observar que o tipo E, que caracteriza o professor com comportamentos relacionados à abordagem sociocultural, aparece com freqüência maior na $3^{\text {a }}$ série. Os outros tipos de professores aparecem com a mesma freqüência em ambas as séries.
Tabela 5 - Comparação entre médias da $3^{\mathrm{a}}$ e $4^{\mathrm{a}}$ séries para cada tipo de professor. Campo Grande-MS, 1997

TIPOS DE PROFESS OR

\begin{tabular}{cccccc}
\hline SÉRIE & A & B & C & D & E \\
\hline 3 & $14,25 \mathrm{a}$ & $12,70 \mathrm{a}$ & $11,85 \mathrm{a}$ & $7,55 \mathrm{a}$ & $12,40 \mathrm{a}$ \\
\hline 4 & $15,60 \mathrm{a}$ & $13,95 \mathrm{a}$ & $11,05 \mathrm{a}$ & $7,80 \mathrm{a}$ & $10,75 \mathrm{~b}$ \\
\hline
\end{tabular}

Obs: Médias seguidas pela mesma letra não diferem entre si pelo teste de DUNCAN ( $>00,05)$

$\mathrm{Na}$ análise por proposição, a $3^{\mathrm{a}}$ série percebeu uma predominância de comportamentos que podem ser enquadrados em uma abordagem mais próxima da sociocultural, enquanto que na $4^{\mathrm{a}}$ série prevaleceram os comportamentos mais característicos da abordagem tradicional. Entretanto, na análise quanto aos tipos de professores, não houve diferença significante entre as séries, prevalecendo em primeiro lugar o tipo A (Tradicional).

\section{CONCLUSÕES}

Segundo PIMENTEL (1994, p.20,21), os alunos referem-se a três dimensões fundamentais de um professor qualificado: dimensão dos conteúdos, dimensão das habilidades e dimensão das relações situacionais, entendendo-se por dimensão dos conteúdos, "tudo o que se relaciona com o domínio dos conhecimentos; por habilidades didáticas, tudo o que se refere ao domínio dos instrumentos técnicos metodológicos" e por dimensão das relações situacionais, tudo o que diz respeito ao relacionamento pessoal professor - aluno, enquanto sujeitos envolvidos no todo do processo educacional.

Nas proposições apresentadas aos estudantes, sujeitos do estudo ora em discussão, estavam descritos comportamentos que pertencem às dimensões referidas, e pode-se notar, através dos resultados, que os alunos percebem as dimensões primeiras, no entanto, aqueles comportamentos que expressavam a dimensão das relações situacionais receberam escores menores, especialmente na $4^{\mathrm{a}}$ série. Os itens descreviam comportamentos como: "compreendem o aluno como pessoa e facilitam seu processo de aprendizagem"; "propiciam clima de confiança e respeito mútuo, favorecendo o crescimento dos alunos como pessoas"; "mantêm uma relação horizontal e não imposta com os alunos" e "discutem com os alunos o processo de ensinar e aprender, incentivando a participação e interesse dos mesmos na busca de soluções para questões do ensino e da aprendizagem".

PIMENTEL (1994, p.21), comentando que os 
sujeitos de sua pesquisa também perceberam claramente as dimensões dos conteúdos e das habilidades didáticas entre os professores, mas não a dimensão das relações situacionais, aponta como uma de suas dúvidas: estariam os alunos presos a uma representação tradicionalista dos professores, supervalorizando as duas primeiras dimensões, sem perceber a outra, ou são os professores que valorizam a docência, esquecendo-se da importância do relacionamento humano com os estudantes?

O ensino atual, na opinião de BORDENAVE \& PEREIRA (1994), é altamente pragmático e utilitário, com atenção concentrada na aquisição de conhecimentos e no desenvolvimento de habilidades intelectuais, deixando em segundo plano o desenvolvimento afetivo e emocional do estudante. Um dos pontos positivos observados é o fato de que, mesmo utilizando predominantemente a abordagem tradicional, os docentes do curso estudado, parecem comprometidos com a formação do enfermeiro, pois os alunos discordaram da possibilidade de que existam entre seus professores, comportamentos que possam significar desinteresse pelo ensino, como por exemplo: "evitam interferir na aprendizagem dos alunos, pois não se interessam nem por eles nem pelos conteúdos" e "deixam os alunos escolherem metas e programações, não se comprometendo".

Parece haver diferentes posicionamentos quanto ao ensino, mas os docentes não evitam suas responsabilidades, e acreditamos que o professor universitário não se dedica exclusivamente a "ensinar sua matéria", mas também preocupa-se com o desenvolvimento de atitudes e hábitos morais, com a formação de valores e com comportamentos de participação e cooperação responsáveis.

Importa ainda ressaltar que os alunos estão mais em concordância, do que em discordância, com a observação do comportamento descrito no item 6: "discutem com os alunos os problemas do contexto social em que estão inseridos", podendo significar a busca por novas formas de ensino, para trabalharem junto com os alunos, "avaliando a realidade num ambiente diferente do escolar", para "mudar, transformar-se, reformular valores, crescer, amadurecer" (PIMENTEL, 1994, p.18).

Por outro lado, a multiplicidade de comportamentos, percebida pelos alunos mostra, a transição pela qual os docentes estão passando, apresentando características de várias abordagens e tipos de professores, estando alguns na extremidade que considera o ensino como transmissão de conhecimentos prontos; outros na que considera o conhecimento e o ensino como construção, e outros entre esses dois pólos, almejando mudanças mas ainda presos à segurança do modelo tradicional, onde o professor que utiliza a exposição oral ou preleção como principal atividade, apoia-se nas normas da instituição e no seu poder instituído para isentar-se das discussões com os alunos e reduzir a participação dos mesmos no curso.

Pode-se dizer que no curso de Enfermagem ocorre situações semelhantes àquela descrita por PIMENTEL (1994, p. 57,58) quando fala dos professores de um curso de Medicina, onde chama atenção o fato de que alguns docentes "parecem não unir o que se passa com o ensino, na Clínica Médica, com o que se passa nas salas de aula. Na clínica, o professor tem bem definido seu papel de orientador da aprendizagem e envolve profundamente o aluno na busca de soluções. As operações mentais são reais: o levantamento de hipóteses, a coleta de dados, a articulação, a comparação, a abstração e conceituação são fatos reais e da maior importância", enquanto nas aulas, as situações tendem a ser artificiais, sem o envolvimento do aluno.

Acreditamos, porém, que os membros do corpo docente pesquisado estejam caminhando para alcançar um estágio próximo a uma abordagem mais crítica do ensino que inclua atitudes e comportamentos voltados para a integração professor, aluno e sociedade, comprometidos, pessoal e profissionalmente, com os problemas da Enfermagem.

Observamos que, no conjunto, os alunos percebem que seus professores preocupam-se mais com aspectos técnicos e normativos do curso, mantendo a hierarquia tradicional no que se refere à transmissão dos conteúdos e avaliação, mas às vezes permitem diálogo e participação dos estudantes.

A falta de uma única abordagem definida, segundo a percepção dos alunos com relação aos seus professores, indica que os docentes ainda carecem de reflexão e discussão sobre sua prática pedagógica. As abordagens de ensino podem fornecer ao enfermeiro docente um referencial para a identificação das várias alternativas para ensinar, permitindo a opção por uma delas, após análise dos pontos positivos e negativos de cada uma.

Este estudo apesar de não permitir generalizações externas pelo fato de terem sido coletados dados em um única escola, numa realidade específica, serve como ponto de reflexão para avaliação da prática educativa, não só do corpo docente de referência, mas também de outros professores.

É claro que as mudanças não são produzidas de uma hora para outra, apenas com os resultados das pesquisas. É preciso que tais resultados passem a fazer parte do conhecimento prático dos professores, que se convertam em esquemas de ação.

Para que isso ocorra, os docentes têm que filtrar os dados das pesquisas, reinterpretá-los no contexto de seu trabalho, rejeitá-los ou incorporá-los como alternativas de ação, sem a ilusão de fórmulas mágicas, "conscientes de suas limitações, mas também das 
possibilidades reais acerca daquilo que é possível realizar" (BALZAN, 1989, p.279, 280).

Buscamos uma educação pautada na discussão dos problemas sociais da comunidade e da profissão, que permita a formação de enfermeiros que respondam às necessidades de saúde da população, munidos de instrumental técnico e científico, mas conscientes de sua intervenção como prática social.

\section{FACULTY'S BEHAVIOR IN UNDERGRADUATE NURSING TEACHING: THE STUDENTS' PERCEPTION}

The purposes of the present study are: to identify faculty's predominant behaviors in undergraduate nursing teaching, according to the students' perception and to classify them in different groups of faculty, relating them to the teaching framework. Data were obtained through questionnaires, applied to fifty-two students from the Federal University of Mato Grosso do Sul. Considering the results obtained from both periods, we can conclude that there is a certain plurality in the faculty behaviors, with a predominance of teachers concerned about contents, methods and techniques, with characteristics of the traditional, behaviorist and cognitive frameworks.

KEY WORDS: teaching frameworks, educational behavior, undergraduate teaching

\section{COMPORTAMIENTO DOCENTE EN LA ENSEÑANZA DEL PRE-GRADO DE ENFERMERÍA: LA PERCEPCIÓN DE LOS ALUMNOS}

Este trabajo es un estudio tipo levantamiento, teniendo como objetivos: identificar los comportamientos docentes predominantes en la enseñanza del pre-grado de enfermería, de acuerdo con la percepción de los alumnos, agrupándolos en tipos de profesor y relacionándolos con los abordajes de enseñanza. Los datos fueron obtenidos a través de un formulario, aplicado a 52 sujeitos, alumnos del curso de pre-grado en enfermería de la Universidad Federal de Mato Grosso do Sul. Considerando los resultados obtenidos en ambas series, se puede decir que hay una pluralidad de comportamientos docentes, predominando profesores preocupados con contenidos, métodos y técnicas, con características de las concepciones tradicional, comportamental y cognitiva.

TÉRMINOS CLAVES: teorías de enseñanza, comportamiento docente, enseñanza de enfermería

\section{ANEXO 1}

\section{INSTRUÇ̃̃O:}

Este instrumento faz parte de uma pesquisa cujo objetivo é estudar comportamentos dos professores de enfermagem, em geral, em situações quotidianas em sala de aula.

Você encontrará proposições sobre comportamentos de professor no processo de ensino-aprendizagem que deverão ser lidas com atenção, em primeiro lugar. Em seguida você vai marcar sua resposta sobre a atuação do professor em relação a cada uma das proposições. Há quatro possibilidades de resposta, conforme escala abaixo.

Não existem respostas certas ou erradas e só interessa sua opinião sincera. Esteja certo de que respondeu a todas às proposições, não deixando nenhuma em branco.

Você não precisa se identificar, apenas assinalar o período escolar que está cursando: semestre/ano.

Muito obrigado pela colaboração.

\section{1-DISCORDO TOTALMENTE 3-COHCORDO PARCIALMENTE 2-DICORDO PARCIALMENTE 4-COHCORDO TOTALMENTE}

\section{SEUS PROFESSORES EM GERAL:}

1. Compreendem o aluno como pessoa e facilitam seu processo de aprendizagem.

2. Cumprem a tarefa de ensinar a maténa e certificarn-se que 0 aluno aprendeu a dominar os conteúdos apenas através de provas e testes escritos ou orais.

\begin{tabular}{|c|}
\hline $\begin{array}{l}\text { 3. Favorecem o diálogo com os alunos, no entanto o interesse } \\
\text { maior é pela reprodução dos conteúdos ministrados. }\end{array}$ \\
\hline $\begin{array}{l}\text { 4. Propiciam clima de confiança e respeito mútuo, favorecendo } \\
\text { o crescimento dos alunos como pessoas. }\end{array}$ \\
\hline $\begin{array}{l}\text { 5. Deservolvem relação vertical com os alunos, onde assumem } \\
\text { o papel de autoridade máxima, informando e transmitindo } \\
\text { conteúdos pré-definidos através do mando e da obediência. }\end{array}$ \\
\hline $\begin{array}{l}\text { 6. Discutem com os aluros os problemas do contexto social em } \\
\text { que estão inseridos. }\end{array}$ \\
\hline 7. Mantêm urna relação horizontal e não imposta com os alunos. \\
\hline $\begin{array}{l}\text { 8. Transmitem informações de forma mecânica, com poucas } \\
\text { interpretações. }\end{array}$ \\
\hline $\begin{array}{l}\text { 9. Avaliam os corteúdos de suas exposiçóes, de textos e apostilas } \\
\text { utilizados, preocupando-se em adequá-los à disciplina. }\end{array}$ \\
\hline $\begin{array}{l}\text { 10. São perrissivos demais, deixando os alunos muito àvontade, } \\
\text { dando mais ate nção aos aspectos afetivos que às questões } \\
\text { profissionais. }\end{array}$ \\
\hline $\begin{array}{l}\text { 11. Plarujam e organizam seu trabalho parecendo considerar as } \\
\text { sugestões dos alunos, mas naverdade as decisões são tomadas } \\
\text { por eles. }\end{array}$ \\
\hline $\begin{array}{l}\text { 12. Atribuem pouca importância aos objetivos da disciplina mas } \\
\text { se importam com as necessidades, atitudes e sentimentos dos } \\
\text { estudantes. }\end{array}$ \\
\hline $\begin{array}{l}\text { 13. Visam, predominantemente, o cumprimento dos seus deveres } \\
\text { e do planejamento da disciplina. }\end{array}$ \\
\hline $\begin{array}{l}\text { 14. Evitam interferir na aprendizagem dos alunos, pois não se } \\
\text { interessam nem por eles nem pelos conteúdos. }\end{array}$ \\
\hline
\end{tabular}


15. Preferem não marcar tarefas para casa nem aplicar exames dificeis para não provocar tensões e frustrações nos alunos.

16. Deixam os alunos escolherem metas e programações, não se comprometendo.

17. Encarregam-se de instruir os alunos, transmitindo informações o mais facilmente possivel, para ser amável e querido por todos.

18. Estabelecem objetivos simples e fáceis de serem atingidos e com os quais os alunos concordem.

19. Discutem com os alunos o processo de ensinar e aprender, incentivando a participação e interesse dos mesmos na busca de soluções para questões do ensino e da aprendizagem.

20. Conversam com os estudantes quando eles solicitam apoio e orientação.

21. Corrigem os alunos na presença de outros, sem se preocuparem com os sentimentos deles.

22. Limitam a liberdade para discussões e questionamentos.

23. Utilizam várias técricas de ensino, tentando agradara todos, entretanto transmitem os conteúdos previamente determinados.

24. Preocuparn-se com os resultados das provas (notas) e não com a aprendizagem, mas aplicam provas coerentes com os objetivos da disciplina.

25. Dialogarn com os alunos aparentando postura democrática.

\section{ANEXO 2}

\section{Agrupamentos das proposições em tipos de professor}

TIPO A: comportamentos do professor que transmite informações, utilizando abordagem tradicional.

Proposições:

05- Desenvolvem relação vertical com os alunos, onde assumem o papel de autoridade máxima, informando e transmitindo conteúdos pré-definidos através do mando e da obediência.

08- Transmitem informações de forma mecânica, com poucas interpretações.

13- Visam, predominantemente, o cumprimento dos seus deveres e do planejamento da disciplina.

21- Corrigem os alunos na presença dos outros, sem se preocuparem com os sentimentos deles.

22- Limitam a liberdade para discussões e questionamentos.

TIPO B: comportamentos do professor que se concentra no processo de instrução, utilizando abordagem cognitivista.

Proposições:

02- Cumprem a tarefa de ensinar a matéria e certificam-se que o aluno aprendeu a dominar os conteúdos apenas através de provas e testes escritos ou orais.

11- Planejam e organizam seu trabalho parecendo considerar as sugestões dos alunos, mas na verdade as decisões são tomadas por eles.

14- Evitam interferir na aprendizagem dos alunos, pois não se interessam nem por eles nem pelos conteúdos.

24- Preocupam-se com os resultados das provas (notas) e não com a aprendizagem, mas aplicam provas coerentes com os objetivos da disciplina.

25- Dialogam com os alunos aparentando postura democrática.
TIPO C: comportamentos do professor que se concentra nos conteúdos, utilizando abordagem comportamental.

Proposições:

03- Favorecem o diálogo com os alunos, no entanto o interesse maior é pela reprodução dos conteúdos ministrados.

09- Avaliam os conteúdos de suas exposições, de textos e apostilas utilizados, preocupando-se em adequá-los à disciplina.

17- Encarregam-se de instruir os alunos, transmitindo informações o mais facilmente possível, para ser amável e querido por todos.

18- Estabelecem objetivos simples e fáceis de serem atingidos e com os quais os alunos concordem.

23- Utilizam várias técnicas de ensino, tentando agradar a todos, entretanto transmitem os conteúdos previamente determinados.

TIPO D: comportamentos do professor que se concentra nas necessidades afetivas dos alunos, utilizando abordagem humanista.

Proposições:

10- São permissivos demais, deixando os alunos muito à vontade, dando mais atenção aos aspectos afetivos que às questões profissionais.

12- Atribuem pouca importância aos objetivos da disciplina mas se importam com as necessidades, atitudes e sentimentos dos estudantes.

15- Preferem não marcar tarefas para casa nem aplicar exames difíceis para não provocar tensões e frustrações nos alunos.

16- Deixam os alunos escolherem metas e programações, não se comprometendo.

20- Conversam com os estudantes quando eles solicitam apoio e orientação.

TIPO E: comportamentos do professor que busca uma visão estrutural da sociedade e concentra-se no aluno como pessoa total, utilizando abordagem sociocultural.

Proposições:

01- Compreendem o aluno como pessoa e facilitam seu processo de aprendizagem.

04- Propiciam clima de confiança e respeito mútuo, favorecendo o crescimento dos alunos como pessoas.

06- Discutem com os alunos os problemas do contexto social em que estão inseridos.

07- Mantêm uma relação horizontal e não imposta com os alunos.

19- Discutem com os alunos o processo de ensinar e aprender, incentivando a participação e interesse dos mesmos na busca de soluções para questões do ensino e da aprendizagem.

\section{ANEXO 3}

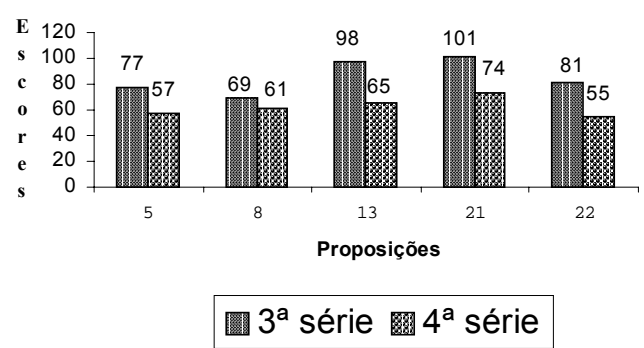

Gráfico 1 - Comparação entre os escores das cinco proposições que constituem o Tipo A $-3^{\text {a }}$ e $4^{\text {a }}$ séries 


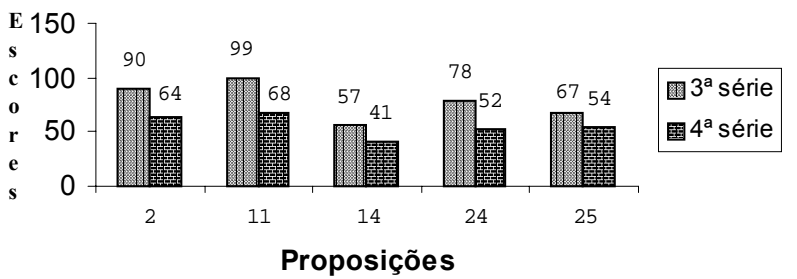

Gráfico 2 - Comparação entre os escores das cinco proposições que constituem o Tipo $B-3^{a}$ e $4^{a}$ séries

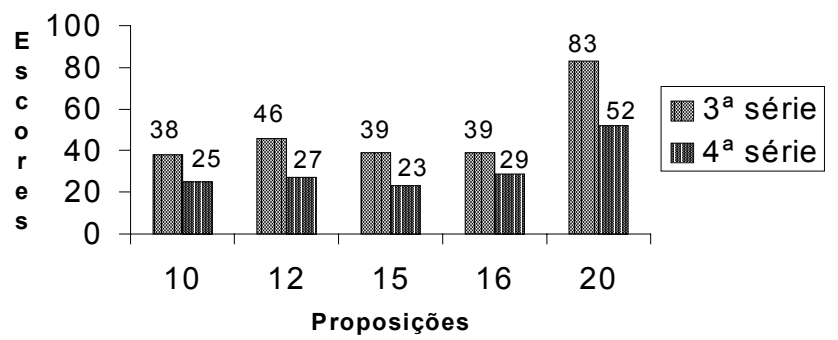

Gráfico 4 - Comparação entre os escores das cinco proposições que constituem o Tipo $D-3^{\mathrm{a}}$ e $4^{\mathrm{a}}$ séries

\section{REFERÊNCIAS BIBLIOGRÁFICAS}

01. ALMEIDA, M. do C. dos S. Tendências pedagógicas na formação do enfermeiro na Paraíba. João Pessoa, 1992. 108p. Dissertação (Mestrado) Centro de Ciências da Saúde, Universidade Federal da Paraíba.

02. BALZAN, N.C. Sete asserções inaceitáveis sobre a inovação educacional. In: GARCIA, W. E. (coord.) Inovação educacional no Brasil: problemas e perspectivas. 2. ed. São Paulo: Cortez/Autores Associados, 1989. p.265-283.

03. BORDENAVE, J.D. Opções pedagógicas. In: ENCONTRO DE EDUCAÇÃO E SAÚDE DA REGIÃO NORTE, Belém, 1982. Anais. Brasília: Centro de Documentação do Ministério da Saúde, 1982. p. 12-16.

04. BORDENAVE, J.D.; PEREIRA, A.M. Estratégias de ensino-aprendizagem. 14. ed. Petrópolis: Vozes, 1994.

05. COLL, C.; SOLÉ, I. A interação professor-aluno no processo de ensino e aprendizagem. In: COLL, C.; PALACIOS, J.; MARCHESI, A. (orgs.) Desenvolvimento psicológico e educação: psicologia da educação. Trad. Angélica Mello Alves. Porto Alegre: Artes Médicas, 1996. v.2, cap. 17, p.281-297.

06. FERRETTI, C.J. A inovação na perspectiva pedagógica. In: GARCIA, W. E. (coord.) Inovação educacional no Brasil: problemas e perspectivas. 2. ed. São Paulo: Cortez/Autores Associados, 1989. p.55-82.

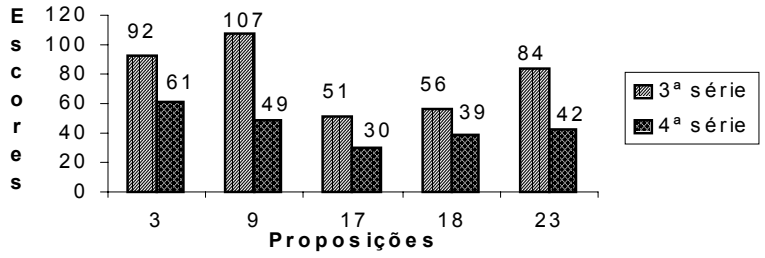

Gráfico 3 - Comparação entre os escores das cinco proposições que constituem o Tipo $C-3^{a}$ e $4^{\text {a }}$ séries

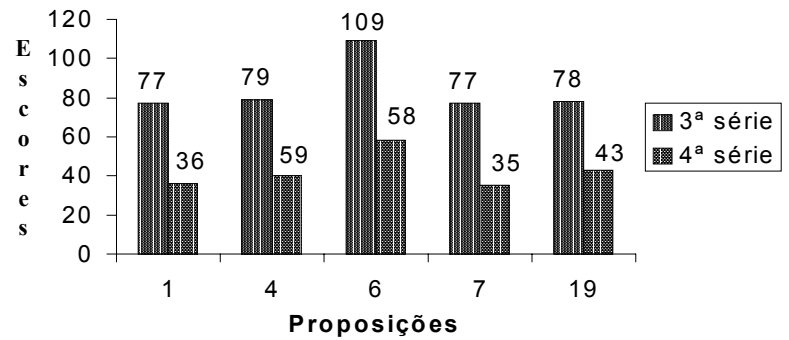

Gráfico 5 - Comparação entre as cinco proposições que constituem o Tipo $E-3^{a}$ e $4^{a}$ séries
07. FREIRE, P.; MACEDO, D. Alfabetização: leitura do mundo leitura da palavra. Trad. Lólio Lourenço de Oliveira. 2. ed. Rio de Janeiro: Paz e Terra, 1990. cap. 1, p.29-43: Repensando a alfabetização: um diálogo.

08. LUCKESI, C.C. O papel da didática na formação do educador. In: CANDAU, V. M. F. (org.). A didática em questão. 12. ed. Petrópolis: Vozes, 1994. p.23-30.

09. MIZUKAMI, M.G.N. Ensino: as abordagens do processo. São Paulo: EPU, 1986.

10. PIMENTEL, M. da G. O professor em construção. 2. ed. Campinas: Papirus, 1994. (Coleção Magistério, Formação e Trabalho Pedagógico).

11. POLIT, D.F.; HUNGLER, B.P. Nursing research: methods, appraisal and utilization. 3rd ed. New York: J. B. Lippincott, 1993. chapter 6, p. 127168: Research design.

12. RODRIGUES, A. A pesquisa experimental em psicologia e educação. Rio de Janeiro: Vozes, 1975.

13. ROGERS, C.R.; ROSENBERG, R.L. A pessoa como centro. São Paulo: EPU, 1977.

14. SAVIANI, D. A filosofia da educação e o problema da inovação em educação. In: GARCIA, W. E. (coord.) Inovação educacional no Brasil: problemas e perspectivas. 2. ed. São Paulo: Cortez/Autores Associados, 1989. p.15-29.

15. SOUZA, M.F. Tendências da pesquisa em Enfermagem. Rev. Esc. Enfermagem USP, v. 26, p. 79-86, out. 1992. Número especial. 